\title{
Toward a Cross-Cultural Training Model for Migrants Entering Oppressive Work Environments
}

\author{
Howard Lorne Martyn ${ }^{1}$ \\ ${ }^{1}$ Guangdong University of Foreign Studies, Guangzhou, Guangdong, People's Republic of China \\ Correspondence: Howard Lorne Martyn, Guangdong University of Foreign Studies, Guangzhou, Guangdong, \\ People’s Republic of China. E-mail: howardeap@gmail.com
}

Received: August 1, 2018

doi:10.5539/ies.v12n2p1
Accepted: September 18, $2018 \quad$ Online Published: January 30, 2019

URL: https://doi.org/10.5539/ies.v12n2p1

\begin{abstract}
This paper examines Indonesian migrant domestic workers' contentment with their sojourn in Hong Kong and factors that inhibit contentment. These factors largely consist of inadequate pre-departure training in Indonesia or training that emphasizes subservience rather than assertiveness, as well as oppressive work environments, underpayment and employer behavior designed to psychologically or physically demean migrants in Hong Kong. The paper proposes a training model with module content based on needs identified during interviews with migrants. Training modules may be presented in Indonesia or Hong Kong by NGO groups and should be process driven and experiential with an emphasis on assertiveness aimed at migrant perspective transformation. Although designed with the Indonesia-Hong Kong situation in mind, this model along with the accompanying modules may be adapted for a variety of situations where migrant workers find themselves in oppressive work environments.
\end{abstract}

Keywords: Asian migrants, domestic workers, labor conditions, Indonesian domestic workers

\section{Introduction}

The training model presented in this paper is based upon data gathered in Hong Kong and Indonesia between 2005 and 2017 (Martyn 2018a, 2018b). Those data collections took place within the context of rapidly increasing migration from Indonesia to Hong Kong. Study participants were domestic workers, hired in Indonesia through employment agencies that specialize in recruitment for the household domestic worker market in Asia. Many of the recruited women hail from rural areas, small villages or towns and have little knowledge of life in a large Indonesian city, let alone in one of the most active and demanding metropolitan areas in the world. Domestic workers are hired on two year Hong Kong government approved contracts, which specify living arrangements, rest days, public holidays and salary. Most employers abide by stipulated conditions and, indeed, many exceed government mandated requirements; however, a substantial number of domestic workers find themselves in situations where employers do not meet their obligations and may be physically or psychologically abusive. The preceding studies were undertaken in order that migrant domestic workers might express, through written narratives, diaries and in focus group meetings, their perceived training needs - not in terms of job function, but in terms of personal emancipation in abusive work situations. I collected data during my volunteer English language teaching classes on Sundays, and during rallies and protests in which participants and I attempted to bring awareness of the situation to a wider public. The result of these studies is the training model and accompanying module outlines below, which may be used by NGOs, churches and interest groups in providing assertiveness training to Indonesian domestic workers residing in, or bound for, Hong Kong. While the training model discusses issues of egalitarian cross-cultural adjustment in both of these situations, it must be recognized that those migrants living in situations of oppression require additional training support. Thus, the model focuses upon training that may be undertaken in order to raise the level of contentment with the migration experience and resist employer oppression, in situations where that may be necessary. Data was gathered through the auspices of Indonesian associations, in particular Serikat Buruh Migran Indonesia (SBMI, Indonesia), and Koalisi Tengara Kerja Indonesia di Hong Kong (KOTKIHO, Hong Kong).

\section{Agents of Subservience: Acts of Resistance}

The employment of foreign domestic workers in Hong Kong takes place within a highly racialized and classed construction. Agencies within Indonesia along with their partners in Hong Kong act as gatekeepers, reinforcing 
attitudes of third world gendered subservience, dedication and most importantly, obedience. When negotiating with employers, agencies talk up the supposed domestic qualities of ethnic and national groups, comparing, for example, stereotypes of Indonesian's 'willingness to tolerate servile attitudes' on the part of the employer, with Filipino's 'higher standards of English language ability', and Sri Lankan's 'willingness to accept below government stipulated salaries'. Some employers are guided into hiring decisions, in part, based on their own predilection for abusive intentions.

The self-representation of individuals within an ethnic group may contain aspects that are, indeed, not dissimilar to the representations put forward by employment agencies, with workers occasionally playing up those 'ideal' stereotypes to garner employer approval, demeaning and demoralizing though that may be. This aspect of agency promotion and employer-employee relationships is not unlike the situation in other developed cities. England and Stiell (1997) examined agency promotion of domestic workers from the Philippines and the Caribbean applying for work in Toronto, Canada, noting that national characteristics of ethnicity, gender and class are often interwoven into the representations, forming a national and ethnic 'ideal' based upon stereotypical employer expectations. Abrantes (2014), studying domestic service suppliers to the European market found that workers were profiled according to preconceived ethnic physical and character traits. Thus neatness, responsible appearance, pleasant attitude, communication skills, willingness to learn, aptitude for teamwork and physical body types were itemized for purposes of labor marketing. Such representations typically result in socially constructed work environments of oppression and privilege.

Employer oppression and privilege are often revealed in non-adherence to government employment standards. Cuban (2015) examining the findings of advocacy organizations in the United States discovered that a significant majority of domestic workers did not receive government mandated holidays, had no health insurance and received no overtime pay. Indeed, many employers in her review did not consider their domestic workers as actual employees, but "in a sense, post-industrial slaves" (p. 4).

Women migrants are seen as extending what they do 'naturally', and at 'no cost' in their homelands. While domestic work has always been difficult to scrutinize due to its privatized nature, middle class families are increasingly desirous to place their domestic workers in positions of invisibility, where it will appear that the homeowner actually does the dirty and sometimes dangerous work in the family home. Ehrenreich and Hochschild (2002) noted that such positioning is particularly prevalent within privatized health care systems and with diplomatic employees who travel with domestic workers.

Resistance to oppression tends to be carried out by the individual worker who has not been strategically trained. But successful resistance is a learned skill that needs to be practiced in supportive group environments, lest it work against the goal of migrant emancipation. Ueno (2009) discusses strategies of resistance used by Indonesian and Filipinos working in Singapore. Many of the described strategies are demeaning: domestic workers hide small amounts of money in the lining of their underwear for fear recruitment agencies in Singapore will confiscate cash and other valuables upon arrival; employees hide their mobile phones underneath mattresses or in baskets of vegetables, fearing confiscation by employers; still, others use public shower facilities, fearing chastisement for excess water consumption. The strategies described are not life affirming, nor do they challenge the status quo, but in fact reaffirm it.

Tennant (1982), writing decades earlier, discusses negotiation in terms of level of assertiveness and corresponding body language. He describes assertiveness as negotiation between two or more parties where all sides wish to maximize benefit while, at a minimum, acknowledge government granted rights, and rights accorded by the United Nations Universal Declaration of Human Rights. Tennant (1982) maintains that it is important for verbal behavior, which he describes as passive, assertive or aggressive, to match non-verbal behaviour - primarily body language and gestures. While assertiveness in both language and body is the goal, an overly aggressive stance may be interpreted as a direct attack causing the other party to reject propositions. Three aspects of training are suggested: training designed to develop negotiating skills, developing an effective and consistent verbal-physical communication strategy, and finally negotiation practice in paired or group situations. Skills pertaining to making complaints, giving criticism and coping with aggression are necessary auxiliary components. Assertiveness is influenced by gender, national culture and ethnicity. However, Parham et al (2015), working with a group of 30 university students, found that education and social status were more likely to determine assertive positioning than gender, national culture or ethnicity, which, though significant, were less impactful. Nevertheless, the authors maintain that assertiveness can be effectively altered through appropriate training.

Abrantes (2014) describes classroom pre-departure hiring agency training of domestic and institutional workers 
that undermine assertiveness and legitimate claim to human rights - "knowledge of rules and procedures . . . training on care or cleaning techniques . . team spirit . . joint learning" (p. 602). Training is intended to enhance competent servitude, not to provide skills that will lead to self-confidence or assertiveness when faced with a hegemonic employer. Martyn (2018a, 2018b) found that among Indonesian workers deployed in Hong Kong, a common complaint is that the required training programs in Indonesia focus on servitude, to the detriment of the worker's legitimate rights.

Investigating the situation of Indonesian domestic workers deployed in Saudi Arabia, Nurchayati (2011) comments that much of the academic literature discussing women migrant workers' rights does not provide tools for emancipation. "One shortcoming of this type of literature [focusing on subjugation of women] is that victimization becomes the central theme and the major "lesson learned"' (p. 481). Indeed, much of the literature fails to describe resistance measures that in themselves do not demean the worker. Although Rachman (2003) argues that individual untrained resistance may, over time, "change the course of events or make a difference to an existing state of affairs" (p. 143), she concludes that "their [migrant workers] actions are too fragmented to challenge the overall institutional factors that form part of the unequal power structures" (p. 144). The training model and modules below, are designed to overcome this inadequacy.

\section{Research Aims}

The purpose of this research is to identify training needs of Indonesian women migrant workers who are either deployed and living in Hong Kong or going through the application and training center process. Interviews were conducted in both Indonesia and Hong Kong. In addition, workers attending language classes in Hong Kong were asked to keep journals detailing issues and incidents that they felt degraded their contentment with their Hong Kong living experience. My research aims are situated within the context of pre-departure or/and deployment.

\section{Pre-departure}

i. To investigate participant-reported factors and pressures influencing decisions to migrate.

ii. To investigate practices among labor brokers and in training centers that participants assert are 'coercive' and are unlikely to foster egalitarian adaptation.

Deployment

i. To investigate the participant-reported factors that influenced their migration experiences, and their 'contentment' with those experiences.

ii. To investigate factors that hinder egalitarian adaptation to Hong Kong society.

\section{Training Package}

i. To develop a model for cross-cultural training that can be applied to either the pre-departure and/or deployment stages of the sojourn.

ii. To develop training modules, which can be applied in either Indonesia or Hong Kong?

\section{A Training Model for Resistance and Empowerment}

The success of an extended sojourn abroad depends upon both internal psycho-social adjustment as well as external influences, such as employer fulfillment, or lack of fulfillment, of government mandated contractual obligations. An overseas posting that results in higher levels of egalitarian cross-cultural adaptation and contentment, must attend to both.

The result of this investigation is the proposal of a training model and outlines for training modules that may be conducted in workshops to raise the likelihood of egalitarian cross-cultural adaptation and 'contentment' with the sojourn. The training model takes at its core, Mezirow's $(1978,1990)$ concepts of transformative learning, conducted within an adult educational context. Although his theories were not written for migrant workers, or to assist migrant workers in cultural adjustment, the concepts are applicable in situations where adults must come to terms with unfamiliar environments and act as agents of social change, both for their own wellbeing, and the well-being of their community. Transformational learning suggests methods by which individuals may liberate themselves from oppressive situations through perspective transformation, which results in a paradigmatic shift in the way situations are viewed, allowing for assertive action in which the aggrieved party repositions themselves from a victim to an equal. Mezirow (2000) incorporates progressive 'psycho-social' stages, through which learners pass in the hopes of achieving higher levels of contentment. He identifies four necessary conditions which guide transformational learning. These are: the presence of 'the other', the opportunity for reflective discourse, a 
mentoring community, and a commitment to act. This paper assumes these conditions as a basis for the model. It layers specific situations present in the Hong Kong context, onto Mezirow's (2000) required conditions. Issues and items identified as deterring egalitarian cross-cultural adaptation or higher levels of contentment are then categorized under Littrel and Salas's (2005) seven training components: didactic, attribution, cultural awareness, experiential, cognitive-behavioral, interaction, and language. The classified issues and items are then used as a basis for the training modules.

Once the conditions outlined by Mezirow (2000) have been met, issues and items identified by participants (Figure 1) and classified (Tables 1-11), may be addressed in workshops, in light of the different social, political and cultural forces that exist in Indonesia and Hong Kong. Participants may be able to objectify their position in society vis-à-vis these forces, which may result in increased ethno relativity and an increased recognition of differing worldviews. Once confidence is gained, migrants may develop the ability to take public action in demanding equality of treatment. This may eventually lead to higher levels of contentment.

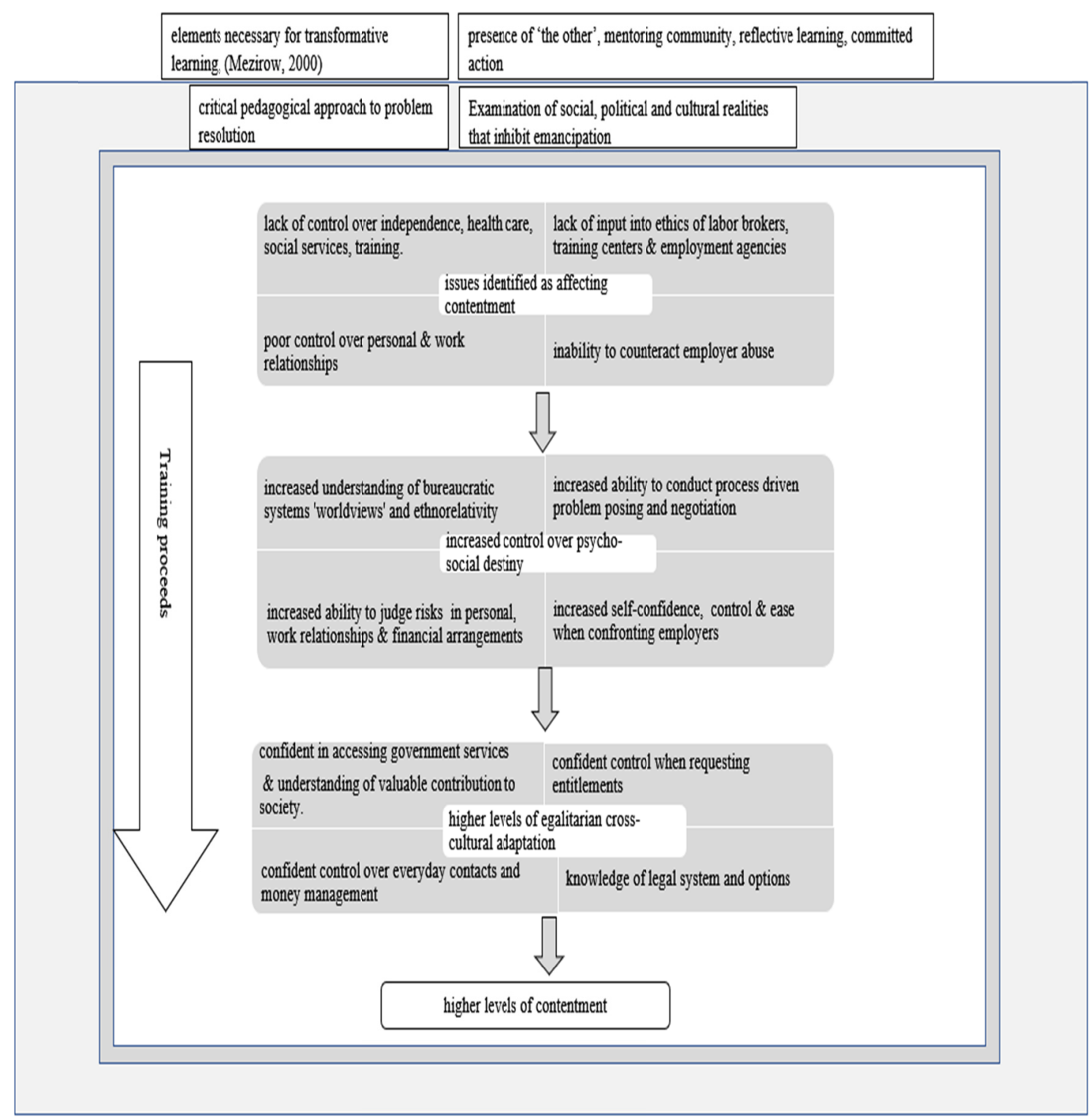

Figure 1. Training model

Within Mezirow's four conditions, I have introduced participant issues and items - disorienting elements - likely to be faced in Cross-Cultural scenarios by migrant workers, and a process that if followed through, is designed to 
bring about higher levels of egalitarian cross-cultural contentment. In order to realize cross-cultural contentment, however, specific training components must be introduced that deal with actual situations mentioned in discussions with Indonesian migrant workers. I have based the components on Littrel and Salas's (2005) $A$ Review of Cross-Cultural Training: Best Practices, Guidelines, and Research Needs.

\subsection{Methodological Training Components}

Participants in this study identified pre-departure training as a major source of problems. These largely revolved around issues of wrong or misleading information, or training designed to abet subservience to employers. At the deployment stage participants identified areas connected with independence, relationships, underpayment, withholding of rest days and intimidation. Undocumented migrants not only felt the stigma of being deemed 'Illegal', but had difficulty accessing health care, with little or no access to social service support, thus contributing to a feeling of devaluation.

Table 1 describes participants' responses to questions regarding training in Indonesia and Hong Kong. They outlined a number of issues and deterrents to adaptation which have been categorized under Littrel \& Salas's (2005) seven training components.

Table 1. Migrant views on accuracy and quality of information, framed within Littrel and Salas's (2005) training components

\begin{tabular}{ll}
\hline $\begin{array}{l}\text { Littrel \& Salas } \\
\text { Training Components }\end{array}$ & $\begin{array}{l}\text { Migrants' Views on the Accuracy/Quality of Information \& Training Provided by Indonesian Labor } \\
\text { Brokers/Indonesian Training Centers, Indonesian NGOs \& Hong Kong NGOs }\end{array}$ \\
\hline Didactic Information & $\begin{array}{l}\text { Information about salary, holidays, labor laws, immigration laws, health and social service care incomplete } \\
\text { or misleading. } \\
\text { Meanings behind some actions are ambiguous. }\end{array}$ \\
Attribution Training & Little training about major cultural differences \\
Cultural Awareness & It is assumed that cross-cultural understanding will occur only on-the-job. \\
Experiential Training & Repatriated migrants teach in training centers. Experienced migrants lead discussions at grassroots \\
Interaction Training & organizations in Indonesia and Hong Kong. \\
Language Training & Variable quality.
\end{tabular}

Information provided by migrants in Table 1 is expanded below, to suggest which items could be included under each of nine training modules. Each module is linked to either Pre-departure (PD) or Deployment (D), depending upon location most appropriate. Training modules may take place in either Hong Kong or Indonesia, although some didactic information is more logically presented in either Indonesia or Hong Kong. The proposed nine training modules are as follows:

i. The Migration Process: Factual Information (Indonesia) (Table 2).

ii. The Migration Process: Factual Information (Hong Kong) (Table 3).

iii. Budgeting and Saving (Table 4).

iv. Clinic and Hospital Procedures (Table 5).

v. Interpretation of Host National Behavior (Table 6).

vi. Cultural Differences (Table 7).

vii. Miscommunication and Stereotyping (Table 8).

viii. Interacting with Community Members (Table 9).

ix. $\quad$ Language Training (Table 10).

Each module might be presented in one workshop, but would more likely require on-going support sessions. Language training would require several workshops.

Tables 2 to 10 specify the 'Link to Research Aim' from which the 'Purpose of Training' was derived, as well as the 'Type of Training' which may be most applicable to the specific training purpose. Finally, each table suggests which government/organization may most appropriately carry out the training.

\subsubsection{Didactic Information}

Factual information may be presented in Indonesia or Hong Kong as appropriate. While this information likely 
requires little interpretation, its conveyance is crucial in order to arm migrants with accurate facts with which to approach individuals, organizations and governments, as necessary. Because such basic information is crucial to an informed migration decision, it is recommended that potential migrants verify facts with third parties.

Table 2. The migration process (Didactic information: Indonesia)

\begin{tabular}{clcc}
\hline $\begin{array}{c}\text { Research } \\
\text { Aim }\end{array}$ & \multicolumn{1}{c}{ Purpose of Training } & Type of Training & Responsibility \\
\hline & *Indonesian migration process & & \\
& requirements & & \\
& $*$ licensing of brokers \& training & & \\
& centers & Discussion and clarification of types and & Indonesian NGOs, Department of Labour \\
PD Aim ii & $*$ pees chargeable by labor brokers & purposes of documents & and Transmigration, \\
D Aim ii & $*$ training centers \\
& chaney lenders, disbursements, & & \\
& $*$ Hong Kong government & & \\
& Employment Contract & & \\
\hline
\end{tabular}

Table 3. The migration process (Didactic information: Hong Kong)

\begin{tabular}{|c|c|c|c|}
\hline $\begin{array}{c}\text { Research } \\
\text { Aim }\end{array}$ & Purpose of Training & Type of Training & Responsibility \\
\hline $\begin{array}{c}\text { PD Aim ii, } \\
\text { D Aim ii }\end{array}$ & $\begin{array}{l}\text { *licensing of HK employment agencies, filing a complaint } \\
\text { against agencies } \\
\text { *Hong Kong banks, finance companies, interest and fees } \\
\text { *Hong Kong Employment Contract } \\
\text { *emergency contacts: police, fire labour, immigration, } \\
\text { hospitals, social welfare, volunteer organizations that work } \\
\text { with migrants } \\
\text { *migrant health insurance, what it covers \& who pays } \\
\text { *legal procedures if: } \\
\text { A. terminated early by employer } \\
\text { B. terminated due to pay dispute, holiday or other dispute } \\
\text { C. physically abused by employer } \\
\text { D. other reasons for desiring early termination } \\
\text { E. end of contract } \\
\text { procedure in case of pending court case }\end{array}$ & $\begin{array}{l}\text { discussion of } \\
\text { documents for } \\
\text { clarification }\end{array}$ & $\begin{array}{c}\text { Hong Kong Labour Department } \\
\text { employment Agencies } \\
\text { Hong Kong Immigration } \\
\text { Department \& Legal Services } \\
\text { Department }\end{array}$ \\
\hline
\end{tabular}

Table 4. Budgeting and saving (Didactic information: Hong Kong)

\begin{tabular}{clcc}
\hline Research Aim & \multicolumn{1}{c}{ Purpose of Training } & Type of Training & Responsibility \\
\hline \multirow{2}{*}{ D Aim i } & *opening bank account \& budgeting & & \\
& $*$ forms for money transfers & discussion and role play & Hong Kong advocacy organizations \\
& $*$ financial goal setting \& extended purchase plans & & \\
\hline
\end{tabular}

Table 5. Clinic and hospital procedures (Didactic information: Hong Kong)

\begin{tabular}{clcc}
\hline $\begin{array}{c}\text { Research } \\
\text { Aim }\end{array}$ & \multicolumn{1}{c}{ Purpose of Training } & Type of Training & Responsibility \\
\hline & *clinic, dental and hospital procedures & & \\
& and charges & & \\
D Aim ii & *hospital forms & lecture followed by discussion, practical outing to & Hong Kong advocacy \\
& *over-the-counter medicines sold in & pharmacy and role play & \\
& Hong Kong & & \\
\hline
\end{tabular}




\subsubsection{Attribution Training}

Attribution training helps sojourners interpret host nationals behavior and points of view.

Table 6. Interpretation of host national behavior (Attribution training)

\begin{tabular}{cccc}
\hline Research Aim & Purpose of Training & Type of Training & Responsibility \\
\hline D Aim i & *interpretation of host nationals behavior. & videos with discussion & Indonesian training centers, Indonesian and \\
& & $\begin{array}{c}\text { reflection of values in host } \\
\text { national behavior. }\end{array}$ & Hong Kong advocacy organizations. \\
& & \\
\hline
\end{tabular}

\subsubsection{Cultural Awareness Training}

Migrants analyze their own culture and cultural specific actions. They attempt to 'objectify' their own behavior, and practice seeing themselves as people from other cultures might see them.

Table 7. Cultural differences (Cultural awareness training)

\begin{tabular}{cccc}
\hline $\begin{array}{l}\text { Research } \\
\text { Aim }\end{array}$ & Purpose of Training & Type of Training & Responsibility \\
\hline \multirow{3}{*}{ D Aim i } & $\begin{array}{c}\text { critical reflection on cultural values and actions } \\
\text { that are culturally inflected - historical and } \\
\text { societal forces that inform values and actions }\end{array}$ & $\begin{array}{c}\text { discussion of values and behaviors } \\
\text { with written narratives and photos as }\end{array}$ & $\begin{array}{c}\text { Indonesian training centers, } \\
\text { Indonesian and Hong Kong }\end{array}$ \\
\hline
\end{tabular}

\subsubsection{Experiential Training}

Experiential training is 'training by doing' or 'training through practice'. It may be undertaken in anticipation of an event or the event in itself may be considered training. It may be undertaken either in Indonesia, prior to staying at the training center and conducted by migrant advocacy organizations, in training centers as part of their program, or in Hong Kong, conducted by migrant advocacy organizations. Table 8 contains some training items that may be conducted experientially.

Table 8. Miscommunication and stereotyping (Experiential training)

\begin{tabular}{|c|c|c|c|}
\hline $\begin{array}{c}\text { Research } \\
\text { Aim }\end{array}$ & Purpose of Training & Type of Training & Responsibility \\
\hline $\begin{array}{l}\text { D Aim i } \\
\quad \& \text { ii } \\
\text { PD Aim i; }\end{array}$ & $\begin{array}{l}\text { *cultural miscommunication } \\
\& \text { stereotyping } \\
\text { *diversity training } \\
\text { *values clarification \& power } \\
\text { relationships. }\end{array}$ & $\begin{array}{l}\text { role play such as 'BaFa BaFa' and 'Power } \\
\text { Leader' (Simulation Training Systems, 2007) } \\
\text { role plays centering on disassociation and } \\
\text { dislocation. }\end{array}$ & $\begin{array}{c}\text { Indonesian training centers, Indonesian and } \\
\text { Hong Kong advocacy organizations. }\end{array}$ \\
\hline
\end{tabular}

\subsubsection{Interaction Training}

Interaction training is designed to allow newcomers to spend time with people from their own culture, but within the host culture. Ideally the mentor should be well adjusted to the host culture and be able to impart key concepts for success to the newcomer.

Table 9. Interacting with community members (Interaction training)

\begin{tabular}{ccc}
\hline $\begin{array}{c}\text { Research } \\
\text { Aim }\end{array}$ & Purpose of Training & Type of Training \\
\hline PD Aim ii & aspects of daily life in Hong Kong - & Outings to markets, shops \& cultural activities \\
D Aim ii & shopping, markets, cultural activities & followed by discussion and analysis. \\
\hline
\end{tabular}

\subsubsection{Language Training}

Language training is designed to give the sojourner skills in either/both Cantonese and/or English. 
Table 10. Language training

\begin{tabular}{cccc}
\hline $\begin{array}{c}\text { Research } \\
\text { Aim }\end{array}$ & Purpose of Training & Type of Training & Responsibility \\
\hline & & classroom, markets, shops, & \\
& cbasic Cantonese. & cultural events & Indonesian training centers, Indonesian and Hong Kong \\
D Aim i & *basic/intermediate & taped interviews with host & advocacy organizations \\
& English & nationals & \\
\hline
\end{tabular}

\section{Discussion: Infusing the Transformative Element into Training}

Workshops in which the modules are presented should be transformational in that migrants "become aware of the forces that have brought us all to the current situation of oppression and take action to change some aspect of the situation" (Van Soest \& Garcia, 2003, p. 94) while at the same time critically reflecting on those actions with an eye towards doing "constructive damage to the status quo" (Finger, 1995). As such, workshops should embody the following characteristics:

- Recognition of multiple 'world views'. A worldview can be defined as "how a person perceives his/her relationship to the world (governments, organizations and individuals)" (Sue \& Sue, 1999, p. 166). Worldviews correlate with the migrants' personal history, upbringing, religion and other factors.

- Workshops should enhance migrants' ability to become interculturally sensitive. Cognition is best transformed from 'ethnocentric' to 'ethnorelative' (Bennett, 1993) so that behavior is recognized within a cultural context.

- Workshops should be 'process driven', and 'experiential' (Mezirow, 1996). Migrants should pose problems (as opposed to trying to solve problems that others' have posed). Migrants must take action, analyze the effect of that action with a view toward modification, and then reapply action. This should occur within the framework of group learning such as described by Brookfield (as cited in Mezirow, 2000).

- Workshops must be non-confrontational and non-judgmental. It is imperative that participants feel 'safe' in their relationship with other group members and are absolutely certain that no scorn will come their way.

- Workshops should follow a clear organization that encompass' multiple learning modes in order to meet migrants' learning preferences, and in order to encompass both cognitive and affective learning. Learning modes may include casual conversation, formalized discussion, short written exercises and longer narratives, such as those described by Brill (2004), Carpenter and Falbo (2003), Louie (2005), and Williams (2004). They might also include references to drawings, photographs, or multi-media such as those described by Gallo (2002), and Spielman (2001). These, in turn, may be framed within Littrel and Salas's (2005) training components.

- The journey toward transformation necessitates willingness to take risks. Because of this, action must be individually defined, but group supported. Results of action should be reported back to the group for discussion and further refinement.

- To the extent possible, workshops should have long term effects. As such, follow-up workshops and an informal 'buddy system' should be established.

One of the aims of the modules above is to build cross-cultural skills and capacity broadly, so that migrants may be better able to cope with issues that arise during the sojourn. If migrants clearly understand their legal entitlements, for example, they would likely feel much more confident in a confrontational situation. Through attribution training they would more likely understand the position of a well-meaning employer who makes an 'odd' request and through cultural awareness training, migrants would learn to objectify their own culture and behavior and see themselves from a Hong Kong person's perspective.

The other aim is to provide more specific skills, aimed at procedural necessities, such as filling in forms at clinics and banks, and requesting information concerning over-the-counter medicine. Many Indonesian migrants will have had no experience in carrying out these tasks, so it is vital that confidence and capacity are built in this area.

\section{Conclusion}

Although theories and envisioned processes involved in sojourner adjustment have evolved since the mid 1950's, 
these generally assume a neutral host environment. However, migrants from Indonesia to Hong Kong often face employers and social situations which are primarily interested in them adopting the "technologies of servitude" (Rudnyckyi, 2004, p. 421), thereby assuming a posture of subservience. In order to adequately resist or overcome this deterrent to egalitarian cross-cultural adaptation, NGOs need to incorporate transformative learning into their programs. The use of narratives to problematize situations that can be discussed in groups from which group and individual action plans can be developed may be a useful first step in the long road toward migrants' contentment.

\section{References}

Abrantes, M. (2014). Domiciliary care and migrant domestic workers: Grasping the new institutional landscape. Journal of Sociology and Social Policy, 34(9/10), 593-608. https://doi.org/10.1108/IJSSP-04-2013-0050

Bennett, M. J. (1993). Toward a developmental model of intercultural sensitivity. In R. M. Paige (Ed.), Education for the intercultural experience (pp. 249-261). Yarmouth: Intercultural Press.

Brill, F. (2004). Thinking outside the box: Imagination and empathy beyond story writing. Literacy, 38(2), 83-89. https://doi.org/10.1111/j.0034-0472.2004.03802004.x

Carpenter, W., \& Falbo, B. (2003). Literacy, identity, and the "successful" student writer. In B. Williams (Ed.), Composing identities: Our selves, our lives, our students.

Ehrenreich, B., \& Hochschild, A. (Eds.). (2002). Global women: Nannies, maids, and sex workers in the new economy. New York: Metropolitan Books.

England, K., \& Stiell, B. (1997). "They think you're as stupid as your English is": Constructing foreign domestic workers in Toronto. Environment and Planning A: Economy and Space, 29(2), 195-215. https://doi.org/10.1068/a290195

Finger, M. (1995). Adult education and society today. International Journal of Lifelong Learning., 14(2), 110-119. https://doi.org/10.1080/0260137950140202

Gallo, M. (2002). Picture this: Immigrant workers use photography for communication and change. Journal of Workplace Learning, 14(2), 49-57. https://doi.org/10.1108/13665620210419293

Littrell, L., \& Salas, E. (2005). A review of cross-cultural training: Best practices, guidelines, and research needs. Human Resource Development Review, 4(3), 305-334. https://doi.org/10.1177/1534484305278348

Louie, B. (2005). Development of empathetic responses with multicultural literature. Journal of Adolescent \& Adult Literacy, 48(7), 566-578. https://doi.org/10.1598/JAAL.48.7.3

Martyn, H. L. (2018a). Narratives as catalysts for transformation and social action planning within the Hong Kong Indonesian migrant community. Asian Social Science, 14(6), 106-117. doi:org/10.5539/ass.v14n6p106

Martyn, H. L. (2018b). Voices of Indonesian migrant workers at home and abroad. Asian Social Science, 14(8), 119-131.

Mezirow, J. (1978). Education for perspective transformation: Women re-entry programs in community college. New York: Teachers College, Columbia University.

Mezirow, J. (1990). Fostering critical reflection in adulthood: A guide to transformative and emancipatory learning. San Francisco: Jossey-Bass.

Mezirow, J., \& Associates. (2000). Learning as transformation. San Francisco.: Jossey-Bass.

Nurchayati. (2011). Bringing agency back in: Indonesian migrant domestic workers in Saudi Arabia. Asian and Pacific Migration Journal, 20(3-4). https://doi.org/10.1177/011719681102000311

Parham, J., Lewis, C., Fretwell, C., Irwin, G., \& Schrimsher, M. (2015). Influences on assertiveness: Gender, national culture, and ethnicity. Journal of Management Development, 34(4), 421-439. https://doi.org/10.1108/JMD-09-2013-0113

Simulation Training Systems. (2007). BaFa BaFa. Retrieved from http://www.stsintl.com

Spielman, J. (2001). The family photography project: "We will just read what the pictures tell us.". Reading Teacher, 54(8), 762-770.

Sue, D., \& Sue, D. W. (1999). Counselling the culturally different: Theory and practice (3rd ed.). New York: Wiley. 
Tennant, C. (1982). Assertiveness training-A practical approach. Journal of European Industrial Training, 6(6), 3-6. https://doi.org/10.1108/eb002396

Ueno, K. (2009). Strategies of resistance among Filipina and Indonesian domestic workers in Singapore. Asian and Pacific Migration Journal, 18(4), 497-517. https://doi.org/10.1177/011719680901800403

Van Soest, D., \& Garcia, B. (2003). Diversity education for social justice. Mastering teaching skills. Alexandria: Council on Social Work Education.

Williams, B. (2004). Heroes, rebels, and victims: Student identities in literacy narratives. Literacy \& Identity, $47(4), 342-345$.

\section{Copyrights}

Copyright for this article is retained by the author(s), with first publication rights granted to the journal.

This is an open-access article distributed under the terms and conditions of the Creative Commons Attribution license (http://creativecommons.org/licenses/by/4.0/). 